\title{
Survey for evaluating perceptions of workers in nursing homes regarding swallowing disorders
}

\author{
Sun-Young Yim ${ }^{1}$, Ree-Aie Ju², Hyo-Jin Son ${ }^{3}$ Inn-Im Park ${ }^{4}$, Yu-Ri Heo ${ }^{1,3}$, Mee-Kyoung Son ${ }^{1,3 *}$ \\ ${ }^{1}$ Department of Prosthodontics, School of Dentistry, Chosun University, Gwangju, Korea \\ ${ }^{2}$ Agape Silver Center, Gwangju, Korea \\ ${ }^{3}$ Oral Biology Research Institute, Chosun University, Gwangju, Korea \\ ${ }^{4}$ Goodface Dental Clinic, Seoul, Korea
}

This research is intended to be base data for suggestions about the role of dentists and new treatment methods for patients with swallowing disorders as a rehabilitation for oral functions under long-term care insurance for the elderly by investigating and evaluating the perception of the aged with dysphagia by the workers in nursing facilities. We analyzed 436 questionnaire surveys conducted on nursing facilities affiliated to the Association of Gwang-ju Welfare for the Aged through email from August 7, 2017, to September 8, 2017. Many workers in nursing facilities were concerned with the swallowing disorders among the patients, and the treatments they would request from the nursing-home dentists were dental check-ups, oral hygiene management, and eating-swallowing guidance and consultation. Our findings show that reconsideration of the role of the dentists is demanded, along with the awareness of nursing facility workers on swallowing disorders and the need for relevant treatments. Also, we must secure the institutional basis where the cooperation of the nursing and medical teams can take place.

Key Words: Aging, Aspiration pneumonia, Deglutition disorders

(c) This is an open-access article distributed under the terms of the Creative Commons Attribution Non-Commercial License (http://creativecommons.org/licenses/by-nc/4.0) which permits unrestricted noncommercial use, distribution, and reproduction in any medium, provided the original work is properly cited.

\section{서 론}

최근 노인 인구의 급격한 증가에 따라 다양한 분야에서 고령 화로 인한 문제가 제기되고 있다. 통계청에 의하면 우리나라는 올해 전체 인구 중 65 세 이상 노인 인구가 $14 \%$ 이상을 차지하는 고령사회에, 2025년에는 20\% 이상인 초고령 사회에 도달할 것 으로 예상된다[1].

인구의 고령화에 따라, 여자는 86세, 남자는 80세로 기대 수 명도 증가하고 있으며 이로 인해, 경제, 산업, 복지, 교육, 문화 등 사회시스템 전반에서의 변화가 진행되고 있다. 노인의 삶의 질(quality of life)에 대한 관심과 이의 향상을 위한 의료, 복지 서비스 정책 또한 새롭게 개발되고 시행되고 있다. 특히, 건강한 노년생활을 영위하기 위하여, 구강 건강의 중요성이 지속적으 로 부각되고 있다. 건강한 치아로 음식을 잘 씹고 섭취할 수 있 는 것은 전신건강과도 직결되는 필수요건이다. 치아 결손은 저 작 기능 이상으로 인한 영양 결핍 외에도 급격한 외모의 변화와 발음의 문제를 야기하며, 이는 노인의 심리적 위축과 사회적 활 동을 제한함으로서 노인의 삶의 질을 급격히 저하시키는 요인 이 된다.

이와 같이 노인의 삶의 질 향상을 위해 구강 건강과 구강위생

Received April 25, 2018; Revised June 29, 2018; Accepted June 29, 2018

Corresponding author: Mee-Kyoung Son, Department of Prosthodontics, School of Dentistry, Chosun University, 303 Pilmun-daero, Dong-gu, Gwangju 61452, Korea.

Tel: +82-62-220-3820, Fax: +82-62-227-7811, E-mail: son0513@chosun.ac.kr

Copyright $\odot$ 2018, Oral Biology Research Institute 
관리의 중요성이 부각되면서, 치과 의료 및 복지 정책에도 변화 가 요구되고 있다. 의사, 한의사로 제한되어 있던 촉탁의 제도가 2016년에 치과의사를 포함하여 확대하게 되었으며 개정된 것 도 이러한 사회적 요구에 의한 결과 중 하나라고 볼 수 있다. 치 과 촉탁의 제도는 거동이 불편하여 병·의원 내원이 힘든 노인환 자들을 위해 장기요양시설에 치과의사가 직접 방문하여 진찰과 일부 진료행위가 가능하도록 한 의료복지제도이다. 치과 촉탁 의 제도하에서 치과의사가 시행할 수 있는 진료의 범위는 구강 위생관리, 통증조절, 구강기능회복 증진, 처방 등과 관련된 내용 과 환자 및 시설 근무자 교육 등이 있다(Table 1)[2].

이 중 구강기능회복증진을 위한 치료 항목에 섭식연하장애 지도와 시설 근무자 교육 항목에 섭식연하장애에 의한 다양한 증상의 조절 방법이 포함되어 있는 것을 눈여겨볼 필요가 있 다. 섭식연하장애는 삼킴을 위한 준비 과정부터 삼키는 것에 관 련된 모든 행위 및 감각에서 발생하는 어려움을 이야기한다[3]. 노화가 진행됨에 따라 삼킴과 관련된 근육들의 근력 저하로 연

Table 1. Dental examination in sanatorium

\begin{tabular}{|c|c|}
\hline Treatment & Contents \\
\hline Oral health assessment & Oral examination \\
\hline Oral hygiene management & $\begin{array}{l}\text { Oral hygiene management } \\
\text { Oral malodor management } \\
\text { Dentures hygiene management } \\
\text { and instruction }\end{array}$ \\
\hline Oral topical pain management & $\begin{array}{l}\text { Oral soft tissue focus prevention } \\
\text { and treatment } \\
\text { Treatment on wound by dentures } \\
\text { Treatment on side effect by } \\
\text { medication }\end{array}$ \\
\hline $\begin{array}{l}\text { Improvement in oral function } \\
\text { recovery }\end{array}$ & $\begin{array}{l}\text { Xerostomia treatment } \\
\text { Instruction on dysphagia }\end{array}$ \\
\hline Optional treatment & $\begin{array}{l}\text { Dentures adjustment } \\
\text { Oral hygiene management by } \\
\text { specialists }\end{array}$ \\
\hline \multicolumn{2}{|l|}{ Prescriptions } \\
\hline Educational activities & Contents \\
\hline $\begin{array}{l}\text { Educational activities for } \\
\text { residents }\end{array}$ & $\begin{array}{l}\text { Oral hygiene training } \\
\text { Dentures management } \\
\text { Training on strengthening } \\
\text { muscles around mouth }\end{array}$ \\
\hline $\begin{array}{l}\text { Educational activities for care } \\
\text { workers }\end{array}$ & $\begin{array}{l}\text { Daily oral hygiene management } \\
\text { Oral care product management } \\
\text { Managing methods on variety of } \\
\text { symptoms caused by dysphagia }\end{array}$ \\
\hline
\end{tabular}

하 조절 능력이 감소하고 연하 후 식괴 잔여물이 증가하는데 이 러한 노화 현상에 따라 건강한 노인에게서도 섭식연하장애가 발생하게 된다. 식괴가 구강, 인두, 식도 등에 오래 남게 될 경 우 기도로 잘못 들어가 질식이나 흡인성 폐렴을 야기할 수 있으 며 이로 인한 합병증은 노인 사망의 높은 비율을 차지하고 있다 [4,5].

노인 인구의 증가에 따라 우리나라는 2008년 7월 1일 노인장 기요양보험 제도가 시행되어, 다양한 노인성 질환을 갖는 노인 중 시설 서비스요양등급이 인정되는 노인들은 노인요양시설에 서 생활할 수 있게 되었다. 노인요양시설에 상주하는 노인들의 삼킴 장애 관련 연구에 따르면 40\%-60\%가 연하 곤란을 겪고 있다고 보고된 바 있다[6]. 일본 후생성의 연구에 의하면 70세 를 전후하여 섭식연하장애 유병률이 6배 이상 증가된다고 보고 된 바 있으며, 국내 재가 노인의 연하장애 유병률에 대한 연구에 서도 65 세 이상 노인들의 연하장애평가 결과 $33.7 \%$ 의 유병률을 보고한 바 있다[7].

이와 같이 노인환자에서 섭식연하장애와 이로 인한 질식이나 폐렴의 유병률이 증가됨에도 불구하고, 이에 대한 치료나 섭식 연하지도, 교육의 중요성에 대한 사회적 인식은 매우 미흡하다. 따라서, 본 연구의 목적은 노인환자의 섭식연하지도와 교육의 필요성과 이를 시행하는 치과 촉탁의의 역할의 중요성을 이해 시키기에 앞서, 고령자 삼킴 장애에 대한 요양시설 종사자들의 인식을 조사하고 평가함으로서 노인장기요양보험하에서 치과 촉탁의 제도의 활성화와 구강기능재활회복에 대한 치과의사들 의 새로운 진료 모델을 제안하는 기반 자료로 사용하고자 한다.

\section{대상 및 방법}

\section{연구 대상 및 절차}

광주광역시 노인복지협회 소속의 요양시설 중 24 개소 총 436 명의 요양시설 종사자를 대상으로 설문조사를 시행하였다. 연 구기간은 2017년 8월 7일부터 2017년 9월 8일까지 시행하였 다.

\section{연구 도구}

설문지는 삼킴 장애 진단과 치료에 대한 언어치료전공자의 인 식 및 현황을 조사한 연구에서 사용되었던 설문지[8]를 참고하 여 작성하였고 치과의사의 역할과 관련된 항목을 추가하여 구성 하였다. 설문의 문항은 응답자의 기초 정보 관련 3 문항, 치료 환 자의 삼킴 장애 발생 및 상담 관련 3 문항, 삼킴 장애 환자 관련 교육 관련 2문항, 치과 촉탁의 관련 2문항으로 이루어졌다. 
Table 2. General characteristics of subjects $(n=436)$

\begin{tabular}{|c|c|}
\hline Variable & Value \\
\hline \multicolumn{2}{|l|}{ Age (y) } \\
\hline $20-29$ & $20(4.6)$ \\
\hline $30-39$ & $33(7.6)$ \\
\hline $40-49$ & $78(17.9)$ \\
\hline $50-59$ & $208(47.7)$ \\
\hline $60-69$ & $87(20.0)$ \\
\hline $70+$ & $3(0.7)$ \\
\hline Nonresponse & $7(1.6)$ \\
\hline \multicolumn{2}{|l|}{ Gender } \\
\hline Male & $33(7.6)$ \\
\hline Female & $387(88.8)$ \\
\hline Nonresponse & $16(3.7)$ \\
\hline \multicolumn{2}{|l|}{ Job } \\
\hline Super intendant & $12(2.8)$ \\
\hline Care worker & $220(50.5)$ \\
\hline Social worker & $48(11.0)$ \\
\hline Physical therapist & $10(2.3)$ \\
\hline Nurse \& Nurse assistant & $36(8.3)$ \\
\hline Others & $60(13.8)$ \\
\hline Nonresponse & $50(11.5)$ \\
\hline
\end{tabular}

Values are presented as number (\%).

\section{분석 방법}

응답자의 기초 정보 관련 문항 및 선택형 문항에 대해서는 빈 도 분석을 시행하였고 순위를 기재하는 문항에 대해서는 각 순 위를 점수화하여 합산하여 분석하였다.

\section{결 과}

\section{설문 응답자의 일반적 특성}

설문 응답자의 연령 분포는 51-60세가 227명(52.1\%)으로 가 장 많았고 41-50세 93명(21.3\%), 61-70세 41명(9.4\%), 31-40 세 39명(8.9\%), 21-30세 25명(5.7\%), 71-80세 7명(1.6\%), 무응 답 3명 $(0.7 \%)$ 으로 나타났으며 평균 연령은 51.9세였다. 설문 응 답자의 성별 분포는 여성 387 명(88.8\%), 남성 33명(7.6\%), 무응
Table 3. Awareness of swallowing disorders $(n=436)$

\begin{tabular}{lc}
\hline \multicolumn{1}{c}{ Variable } & Value \\
\hline Concerned about patients dysphagia & $416(95.4)$ \\
Yes & $20(4.6)$ \\
No & \\
Problems caused by patient's dysphagia & $296(67.9)$ \\
Yes & $136(31.2)$ \\
No & $4(0.9)$ \\
Nonresponse & \\
Consultation in case of swallowing disorders & \\
in patients & $315(72.2)$ \\
Yes & $118(27.1)$ \\
No & $3(0.7)$ \\
Nonresponse &
\end{tabular}

Values are presented as number (\%).

답 7명(1.6\%)으로 여성의 비율이 매우 높았다.

설문 응답자의 직업 분포는 요양보호사 직업군이 220 명 (50.5\%)으로 가장 많았고 기타 직업 60명(13.8\%), 사회복지사 48명(11.0\%), 간호사 및 간호조무사 36명(8.3\%), 시설장 12 명 (2.8\%), 물리치료사 10 명(2.3\%)순으로 뒤를 이었다(Table 2).

\section{삼킴 장애 발생 및 상담}

돌보고 있는 환자가 음식물을 삼킬 때 삼킴 장애에 대해 염려 한 적이 있냐는 설문에 '네’라고 답한 응답자가 416명(95.4\%), ‘아니오’라고 답한 응답자가 20명(4.6\%)으로 조사되었다. 환자 의 삼킴 장애로 인해 문제가 발생한 적이 있는지 묻는 설문에 '네’라고 답한 응답자가 296명(67.9\%), '아니오'라고 답한 응답 자가 136 명(31.2\%)이었다.

환자의 삼킴 장애가 염려될 때 상담 가능한 전문가 또는 전 문기관이 있는지 묻는 질문에 '네'라고 답한 응답자가 315 명 (72.2\%), '아니오'라고 답한 응답자가 118 명(27.1\%)이었다 (Table 3).

\section{삼킴 장애 환자 관련 교육}

삼킴 장애 환자의 훈련 및 재활 관련 교육 경험을 묻는 질문에 는 276명(63.3\%)이 '네'라고 답했으며, 필요성을 묻는 질문에는 427명(97.9\%)이 '네'라고 답했다(Table 4). 각 직업별로 교육 유 무를 묻는 질문에 요양보호사가 220 명 중 154 명, 물리치료사가 
10 명 중 7 명이 ‘네’라고 답하여 $70.0 \%$ 로 가장 높았으며 사회복 지사는 48 명 중 16 만이 그렇다고 답하여 $33.3 \%$ 로 가장 낮았다 (Fig. 1).

\section{치과 촉탁의}

요양기관 내 치과 촉탁의 의뢰가 가능함을 알고 있나는 질문 에 '그렇다'고 답한 응답자는 256명(58.7\%)였고 '모른다'라고 답한 응답자는 177 명(40.6\%)이었다(Fig. 2). 응답을 직업에 따 라 분류한 결과 시설장은 12 명 중 10 명(83.3\%)이 '그렁다' 고 답 하여 가장 높은 비율을 보였으나 물리치료사는 '그렇다'고 답한 응답자가 10 명 중 3 명, $30.0 \%$ 로 가장 낮았다(Fig. 3).

치과 촉탁의를 통해 치료를 요청한다면 필요로 하는 진료 내 용의 순위를 기재하는 문항은 1 위를 5점, 2 위를 4 점, 3 위를 3점, 4위를 2점, 5위를 1점으로 배정하여 총 점수를 합산하였다. 그 결과 A. 구강 검진 및 구강 위생 관리(317점)가 가장 높은 점수 를 받았으며 그 다음으로 C. 섭식연하 지도 및 상담(289점). B. 틀니 관련 치료 및 지도(242점), D. 구강건조증 및 연조직 처치 (166점), E. 요양보호사 및 입소자 상담 및 교육(156점)순으로 높은 점수를 받았다(Fig. 4).

\section{고 찰}

‘입으로 먹을 수 있다'는 젊고 건강한 사람들에게는 당연한 이 야기일 수 있지만 노인이나 구강기능장애 환자들에게는 삶의 질과 직결하는 중요한 문제이다. 음식물이나 타액이 인두를 통 해 식도로 넘어가지 않고 기도로 넘어가는 경우를 '오연'이라고 한다. 대부분의 건강한 사람들은 식사 중 오연이 발생하는 경우, 기침 반사를 통해 음식을 배출하고 이러한 현상을 '사레 듦'이 라고 표현한다. 반면, 노인들의 경우는 근력 감소뿐 아니라 감각 및 반사 기능의 둔화로 인해 ‘사레들지 않은 오연', 즉 스스로 인
식하거나 반응하지 못하는 오연이 발생되며 이로 인해 기도로 들어간 타액이나 음식물이 배출되지 못해 질식이나 흡인성 폐 렴이 발생할 수 있다. 노인요양시설 입소 노인의 절반 이상이 이 러한 삼킴 장애로 인한 곤란을 겪고 있으며, 요양시설 종사자 또 한 환자의 삼킴 장애에 대한 염려를 하지 않을 수 없을 만큼 삼 킴 장애는 노인 환자에게 있어 주요한 문제 중 하나이다. 본 연 구의 결과에서도 대부분의 요양시설 종사자들이 돌보는 환자들 의 삼킴 장애를 염려한 적이 있다(95.4\%)고 응답한 것을 볼 때, 실제 요양시설에서 식사 시 이러한 문제를 갖는 환자들의 비율 이 매우 높다는 것을 유추해볼 수 있다.

일본은 우리나라보다 고령화가 더 앞서 진행되어 이를 대비 하기 위한 다양한 의료지원시스템을 구축해왔다. 일본은 섭식 연하장애에 대한 시스템을 구축하기에 앞서, 실태파악을 위해 2006년 처음 타마 북서부 보건의료권의 109 개 노인요양시설을 대상으로 실태조사를 시행하였다. 오연 즉 삼킴 장애로 인한 문 제에 대한 염려가 있는지 유무를 묻는 질문에서 '그렇다'라고 응 답한 비율은 $60 \%$, 상담 가능한 전문가 및 전문기관이 있는지에 대한 설문에 대해서는 '그렇다'는 응답이 $50 \%$ 로 조사되었다. 이

Table 4. Educations of swallowing disorders $(n=436)$

\begin{tabular}{lc}
\hline \multicolumn{1}{c}{ Variable } & Value \\
\hline Education experiece & $276(63.3)$ \\
Yes & $159(36.5)$ \\
No & $1(0.2)$ \\
Nonresponse & \\
Necessity of education & $427(97.9)$ \\
Yes & $9(2.1)$ \\
No
\end{tabular}

Values are presented as number (\%).

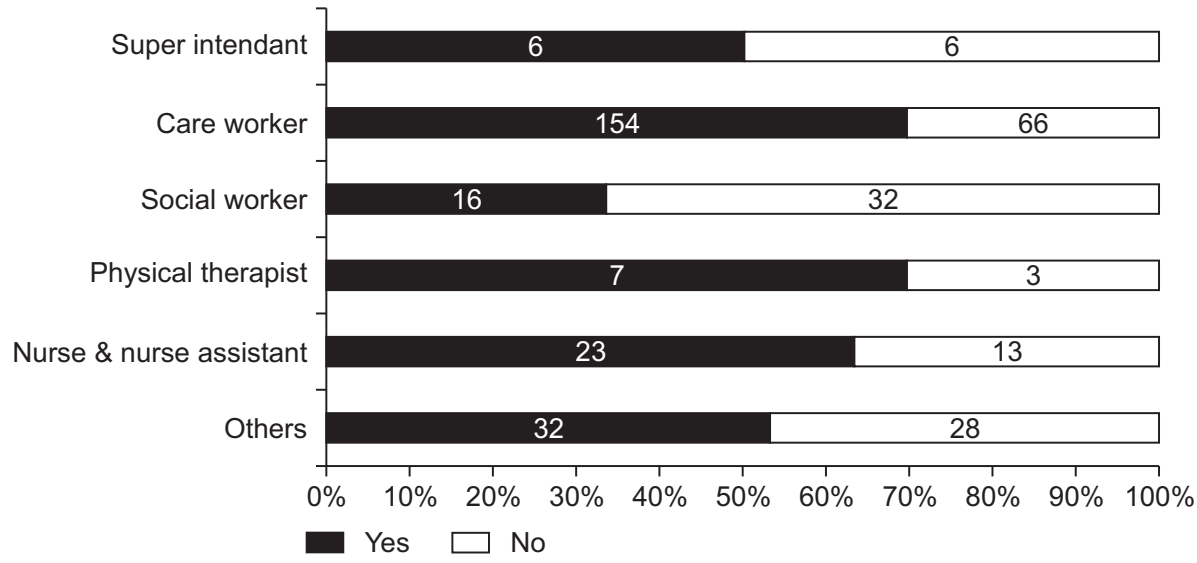

Fig. 1. Education about swallowing disability according to occupation. 
러한 설문조사의 기반과 의료계, 의료수요자들의 요구에 의해 2005년 동경도 타마 지역을 기반으로 2009년까지 지역 일체형 섭식연하 지원 시스템을 구축하였다. 지자체를 중심으로 대학 의 전문 의료진, 행정, 치과의사회, 의사회의 연계 체계를 구축 하여 가이드라인을 수립하고 이를 통해 재택 의료가 활성화 되 었다. 이는 환자들이 직접 치과에 방문하여 치료를 받던 체계와 는 달리 방문치료라는 새로운 진료 모델을 구축하는 초석이 되 었다. 지역 일체형 섭식연하 지원 시스템을 구축하여 운영한 후, 2012년도에 동일한 설문을 시행한 결과, 오연의 염려가 있는지 유무를 묻는 질문에서 '그렇다' 고 응답한 비율은 $70 \%$ 로 증가함 으로서 오연에 대한 인식이 증가했음을 보여주었고, 상담 가능 한 전문가 및 전문기관이 있는지에 대한 설문에 대해서는 '그렇 다’라는 응답이 $70 \%$ 로 증가하여 시스템 구축의 성과를 보여주 었다[9].

본 연구에서, 삼킴 장애로 인한 문제에 대한 염려가 있는지 유 무를 묻는 질문에 ‘그렇다'고 응답한 비율은 $95.4 \%$ 로 일본의 조

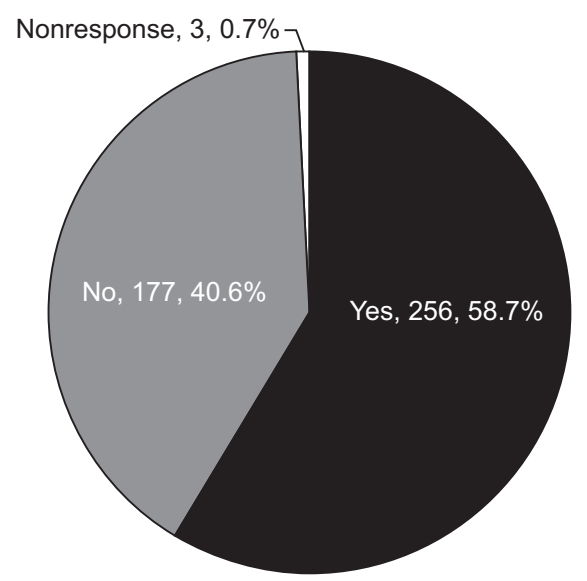

Fig. 2. Distribution of respondents who knew they could refer to a nursing home dentist.
사결과보다 매우 높은 결과를 보여준다. 이는 삼킴 장애에 대 한 교육을 받은 경험(63.3\%) 등을 통해 환자의 식사 시 삼킴 장 애로 인한 문제가 발생할 수 있음을 인식하고 있다는 평가와 함 께, 삼킴 장애의 문제를 보이는 환자가 증가하고 있다는 부정적 인 면을 동시에 내포하고 있다. 상담 가능한 전문가 및 전문기관 이 있는지에 대한 설문에 대해서는 '그렇다'라는 응답이 $72.3 \%$ 로 조사되어 실제 요양 기관과 지속적으로 연계된 의료기관이 존재하거나 또는 정기적으로 방문하는 촉탁의의 존재로 인한 효과로 분석된다. 삼킴 장애 교육에 대한 필요성은 $97.9 \%$ 로 매 우 높게 나타났다. 이는 삼킴 장애로 인한 문제 인식이 증가함을 보여주고 있으며 체계화되고 매뉴얼화된 교육이 필요한 시점 임을 시사한다. 또한 본 연구의 설문조사 결과 요양기관 종사자 40\% 이상이 치과 촉탁의에 대해 모르고 있는 것으로 나타나, 치 과 촉탁의 제도가 새롭게 개정되었음에도 불구하고 치과 촉탁 의 의뢰 가능 여부에 대해서 요양시설 종사자들이 인지하고 있 는 비율이 매우 낮음을 알 수 있다. 치과의사협회의 통계에 의하 면 2017년 12월 기준 촉탁의로 활동하는 치과의사는 17 개 기 관, 15 명으로 매우 적고 치과 촉탁의 제도에 대한 치과의사 내 부의 교육과 인식 또한 현저히 부족한 상황으로 분석되고 있다. 치과 촉탁의에 대해 요청하는 진료로는 구강 검진 및 구강 위생 관리와 섭식연하 지도 및 상담이 높게 나타나, 치과 질환에 대한 처치보다는 예방 치료와 구강기능재활회복 치료에 대한 요구가 더 우선함을 알 수 있다. 이러한 결과를 통해 수요자 중심의 치 료를 위해 다양한 진료 모델을 구축하는 것도 고려해야 할 시점 이라고 판단된다.

건강한 노년생활을 영위하기 위한 의료 및 복지에 대한 관심 이 꾸준히 증가함에 따라, 구강 질환의 치료 및 결손 형태 회복 에 국한되지 않고 재활 및 예방 등 더 확대된 치료가 요구되고 있다. 이러한 수요의 증가에도 불구하고, 고령화에 따라 거동이 불편하여 직접 치과를 내원하지 못하는 노인 환자들이 증가하 고 있어 일반 환자와는 다른 새로운 노인환자 맞춤형 치료패러

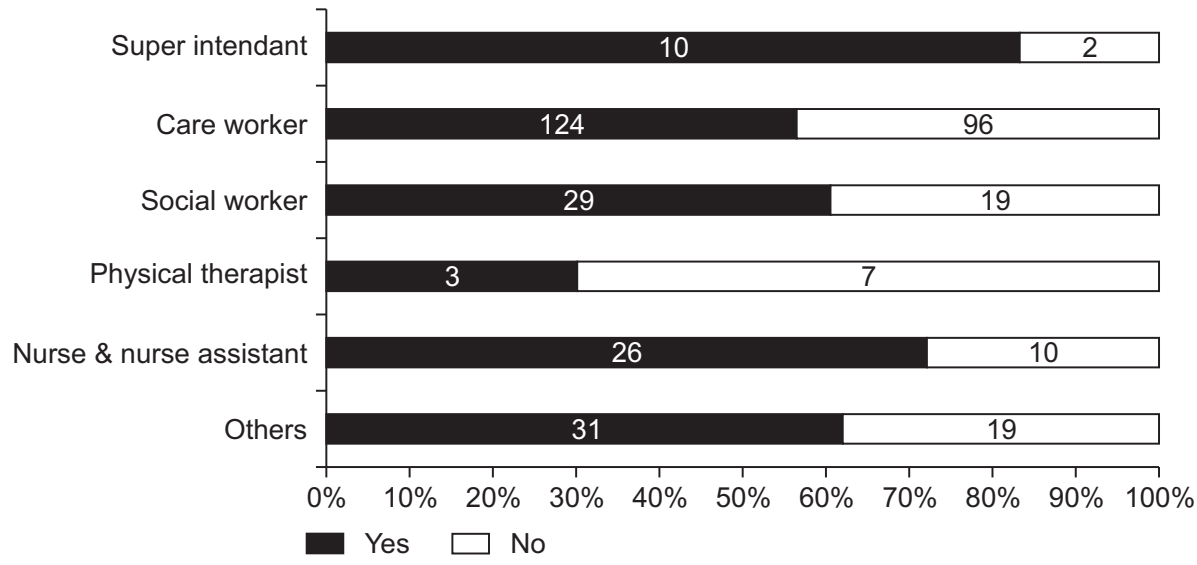

Fig. 3. Distribution of respondents who knew they could refer to a nursing home dentist by job. 


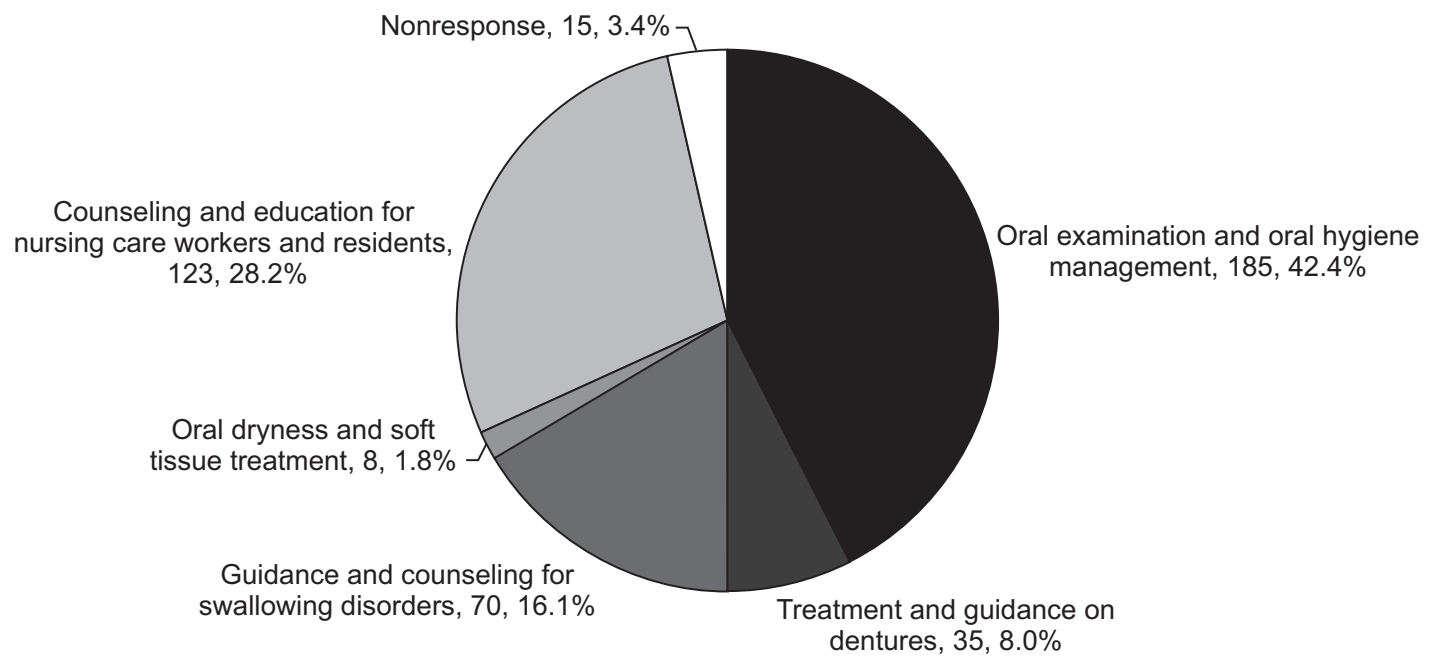

Fig. 4. The priority of the treatment want to ask the nursing home dentist.

다임의 변화가 요구된다. 그 대안으로 치과에 내원하는 환자를 진료하는 것뿐만 아니라 치과 진료가 필요한 환자에게 의사가 찾아가는 방문 진료가 고령화 시대에 새로운 진료 방식으로 요 구될 수 있다. 일본은 오래 전부터 치과방문진료가 시행되고 있 으며 의료보험에 방문진료에 따른 가산이 포함된 수가가 책정 되어 있다. 이에 따라 노인들은 재택 의료 연계 거점 및 지역 포 괄 지원센터를 통하여 자택이나 요양시설에서 방문진료 혜택을 체계적으로 받을 수 있다. 그러나 우리나라의 경우 치과방문진 료가 허용되지 않으며, 2016년 치과 촉탁의 제도가 시행되면서 비로소 일종의 '방문 진료' 형태의 진료 활동이 가능해졌다. 그 러나 진료 대상이 장기요양시설 입소 노인에 제한되며 진료의 범위 또한 한정적이다. 그마저도 진찰료만 수가 책정이 이루어 져 있으며, 행위에 대한 진료 수가는 산정되지 않아 필요한 진료 활동이 이루어지기 어렵다. 그러므로 고령화를 대비한 미래의 진료 형태의 변화에 따른 치과계의 인식 변화 및 교육 뿐 아니라 진료 수가 개선을 포함한 제도적 기반의 마련이 필요한 시점이 다.

본 연구를 기반으로 향후 더 세분화한 설문을 통해 광범위한 지역의 조사와 통계분석이 이루어지고 데이터화 된다면, 치과 의료 정책의 방향성을 제시함에 있어 기반 자료로 사용할 수 있 을 것으로 판단된다. 또한, 요양시설 종사자들의 교육이나 치과 촉탁의 활동을 통한 구강예방진료 및 구강기능재활회복 치료 후 요양시설 상주 노인들의 구강건강의 변화를 후향적으로 분 석하는 추가 연구가 필요할 것으로 생각된다.

본 연구를 위한 설문 조사를 통하여 대다수의 요양시설 종사 자들이 환자의 삼킴 장애로 인한 문제를 염려하고 있으며 관련 교육의 필요성을 인식하고 있음을 알 수 있었다. 하지만 노인요 양시설에서 구강 검진 및 구강 위생 관리, 삼킴 장애 관련 지도
및 상담 등 치과의사의 역할이 필요한 영역이 다수임에도 실제 로 치과의사의 진료나 처치가 이루어지고 있는 부분은 매우 미 비한 상황이다. 이 연구를 기반으로 하여 요양시설 내 치과 촉 탁의의 역할에 있어 섭식연하장애에 대한 환자 지도와 요양시 설 종사자 교육을 위한 다양한 치료 및 교육 매뉴얼이 개발되기 를 기대한다. 또한, 구강기능재활회복에 대한 치과의사의 역할 과 사회적 인식을 확립하기 위하여 치과계의 노력과 제도적 기 반의 확보는 물론이며, 치과 촉탁의를 기반으로 한 방문 진료 형 태의 진료 방식의 변화에 대한 고려가 필요하다.

\section{ACKNOWLEDGEMENTS}

This study was supported by a research fund from Chosun University, 2017.

\section{CONFLICTS OF INTEREST}

The authors declare that they have no competing interests.

\section{ORCID}

Sun-Young Yim
https://orcid.org/0000-0001-7874-8543
Ree-Aie Ju
https://orcid.org/0000-0001-5350-1616
Hyo-Jin Son
https://orcid.org/0000-0002-9553-5336 


\author{
Inn-Im Park \\ https://orcid.org/0000-0001-8410-5798 \\ Yu-Ri Heo \\ https://orcid.org/0000-0002-1806-3822 \\ Mee-Kyoung Son \\ https://orcid.org/0000-0001-9225-1744
}

\section{REFERENCES}

1. Statistics Korea. Population Projections for Korea [Internet]. [cited 2018 Feb 26]. Available from: http://kosis.kr/ statHtml/statHtml.do?orgId=101\&tblid=DT_1BPA002.

2. Kwag JM, Park II, Son MK. Suggestion for understanding and activation of the nursing home dentist system. Oral Biol Res 2017;41:127-133. doi: 10.21851/obr.41.03.2017 09.127.

3. Leopold NA, Kagel MC. Prepharyngeal dysphagia in Parkinson's disease. Dysphagia 1996;11:14-22. doi: 10.10 07/BF00385794.

4. Daniels SK, Ballo LA, Mahoney MC, Foundas AL. Clinical predictors of dysphagia and aspiration risk: outcome measures in acute stroke patients. Arch Phys Med Rehabil
2000;81:1030-1033. doi: 10.1053/apmr.2000.6301.

5. Robbins J, Hamilton JW, Lof GL, Kempster GB. Oropharyngeal swallowing in normal adults of different ages. Gastroenterology 1992;103:823-829. doi: 10.1016/ 0016-5085(92)90013-O.

6. Shanley C, O'Loughlin G. Dysphagia among nursing home residents: an assessment and management protocol. J Gerontol Nurs 2000;26:35-48. doi: 10.3928/0098-913420000801-09.

7. Yang EJ, Kim MH, Lim JY, Paik NJ. Oropharyngeal dysphagia in a community-based elderly cohort: the Korean longitudinal study on health and aging. J Korean Med Sci 2013;28:1534-1539. doi: 10.3346/jkms. 2013.28.10.1534.

8. Yoon JH, Lee HJ. Perceptions on evaluation and treatment of swallowing disorders in speech-language pathologists. Phonetics and Speech Sciences 2013;5:43-51. doi: 10.130 64/KSSS.2013.5.4.043.

9. Son MK, Ko SM, Kwak JM, Park II, So JS, Lee SK, Lee JN. Visiting the Japanese dysphasia rehabilitation treatment, and research and development of the nursing home dentists' dysplasia treatment model. Seoul: Health Policy Institute; 2017. 